Article

\title{
Extraction of Anthocyanins and Total Phenolic Compounds from Açai (Euterpe oleracea Mart.) Using an Experimental Design Methodology. Part 3: Microwave-Assisted Extraction
}

\author{
María José Aliaño-González ${ }^{1}$, Marta Ferreiro-González ${ }^{1}{ }^{\circledR}$, Estrella Espada-Bellido ${ }^{1}{ }^{\mathbb{C}}$, \\ Ceferino Carrera $^{1}$, Miguel Palma ${ }^{1}$, Jesús Ayuso ${ }^{2} \mathbb{D}$, Gerardo F. Barbero ${ }^{1, * \mathbb{D}}$ and José Á. Álvarez ${ }^{2}$ \\ 1 Department of Analytical Chemistry, Faculty of Sciences, University of Cadiz, Agrifood Campus of \\ International Excellence (ceiA3), IVAGRO, 11510 Puerto Real, Cadiz, Spain; \\ mariajose.alianogonzalez@alum.uca.es (M.J.A.-G.); marta.ferreiro@uca.es (M.F.-G.); \\ estrella.espada@uca.es (E.E.-B.); ceferino.carrera@uca.es (C.C.); miguel.palma@uca.es (M.P.) \\ 2 Department of Physical Chemistry, Faculty of Sciences, University of Cadiz, Institute of Biomolecules (INBIO), \\ 11510 Puerto Real, Cadiz, Spain; jesus.ayuso@uca.es (J.A.); joseangel.alvarez@uca.es (J.Á.Á.) \\ * Correspondence: gerardo.fernandez@uca.es; Tel.: +34-956-016355; Fax: +34-956-016460
}

Received: 29 December 2019; Accepted: 23 January 2020; Published: 27 January 2020

check for updates

\begin{abstract}
In this work, two methods based on microwave-assisted extraction techniques for the extraction of both anthocyanins and total phenolic compounds from açai have been developed. For that, a full factorial design (Box-Behnken design) has been used to optimize the following four variables: solvent composition (25-75\% methanol in water), temperature $\left(50-100{ }^{\circ} \mathrm{C}\right), \mathrm{pH}(2-7)$, and sample/solvent ratio $(0.5 \mathrm{~g}: 10 \mathrm{~mL}-0.5 \mathrm{~g}: 20 \mathrm{~mL})$. The anthocyanins and total phenolic compounds content have been determined by ultra high-pressure liquid chromatography and Folin-Ciocalteu method, respectively. The optimum conditions for the extraction of anthocyanins were $38 \% \mathrm{MeOH}$ in water, $99.63^{\circ} \mathrm{C}, \mathrm{pH} 3.00$, at $0.5 \mathrm{~g}: 10 \mathrm{~mL}$ of ratio, while for the extraction of total phenolic compounds they were $74.16 \% \mathrm{MeOH}$ in water, $99.14{ }^{\circ} \mathrm{C}$, $\mathrm{pH} 5.46$, at $0.5 \mathrm{~g}: 20 \mathrm{~mL}$ of ratio. Both methods have shown a high repeatability and intermediate precision with a relative standard deviation lower than $5 \%$. Furthermore, an extraction kinetics study was carried out using extraction periods ranging from 2 min until $25 \mathrm{~min}$. The optimized methods have been applied to açai-containing real samples. The results with such real samples have confirmed that both methods are suitable for a rapid and reliable extraction of anthocyanins and total phenolic compounds.
\end{abstract}

Keywords: açai; anthocyanins; Box-Behnken design; microwave-assisted extraction; phenolic compounds; UHPLC

\section{Introduction}

Nowadays, the use of vegetables and fruits in the treatment and prevention of different chronic diseases, like cancer, based on their interesting antioxidant or anti-inflammatory properties, is increasing [1-5]. Euterpe is a genus of tropical palm trees native to Northern South America that produces three predominant fruits: Euterpe edulis Mart., Euterpe precatoria Mart., and Euterpe oleracea Mart. Different studies have proven the significant properties of those species for the treatment of different diseases [6].

Açai (Euterpe oleracea Mart.) is a spherical dark drupe of a small size $(1.0-1.8 \mathrm{~cm})$ which is very appreciated for its nutritional content such as proteins, carbohydrates, fibers, and fats [7,8]; this is why native people from these regions have included it in their diet for centuries [9]. Several research 
studies have improved our knowledge on its composition and properties and have actually proven that açai is one of the fruit varieties with the richest natural antioxidants content. Its high in vivo and in vitro antioxidant activity (anthocyanins, phenolic compounds, vitamins, etc.) [10] has supported its application in different fields such as cosmetics [11,12], the treatment of neurological disorders [13], or the destruction of carcinogenic cells $[14,15]$, thanks to its high polyphenolic compositions. The antioxidant capacity and anti-inflammatory action of either açai pulp or açai juice have been studied in humans [13] as well as in cell culture models [16].

The recently discovered antioxidant [17], anti-inflammatory [8,18], and anticancer [14,19] properties have been attributed to its high content in anthocyanins and phenolic compounds. Phenolic compounds are generally associated with health-promoting properties and the prevention of different degenerative diseases, since they seem to be responsible for the antioxidant properties and anticancer capacities of certain foods $[20,21]$. The mainly phenolic compounds found in açai are protocatechuic acid, procyanidins, epicatechin, benzoic acid, caffeic acid, chlorogenic acid, ferulic acid, syringic acid, vanillic acid, $p$-coumaric acid, orientin, isoorientin, and vitexin, among others [22,23]. Anthocyanin is a particular variety of phenolic compounds which is associated to the purple color of açai and has exhibited important therapeutic effects such as anti-inflammatory, UV radiation-protective, chemoprotective properties, as well as the reduction of the risk of cardiovascular diseases [24-27].

A total of 20 different anthocyanidins, which are the sugar-free counterparts of anthocyanins, have been identified [28,29], six of them being the most abundant: pelargonidin, delphinidin, cyanidin, petunidin, peonidin, and malvidin. These anthocyanidins differ in the number and position of their hydroxyl and methoxyl groups, and they differ by their glycosyl and aromatic or aliphatic acyl moieties, which results in hundreds of different anthocyanin molecules [23,30,31]. Four main anthocyanins have been identified in açai: cyanidin 3-O-glucoside, cyanidin 3-O-rutinoside, peonidin 3-O-glucoside, and peonidin 3-O-rutinoside [10,32].

Different extraction techniques like Soxhlet [9], supercritical fluid $\mathrm{CO}_{2}$ [33], ultrasound-assisted extraction [34], or pressurized liquid extraction [35] have been used for the extraction of phenolic compounds and anthocyanins from açai. Nevertheless, an exhaustive extraction study on these techniques in order to keep a quality control of the raw material, its storage, and a quality process has not been reported to date.

Microwaves are high-frequency electromagnetic waves located in the radiofrequency regions of the spectrum between radiofrequency and infrared (i.e., between 0.3 and $300 \mathrm{GHz}$ ). In contrast to conventional heating, where the heat penetrates slowly from the outside into the inside medium of a sample, the microwave energy is a "cold" heat-production [36]. The heat is produced right in the core of the object and it spreads from the inside to the outside of a sample [37].

Microwave-assisted extraction (MAE) is an analytical technique based on the extraction of compounds of interest using a solvent and microwave energy. When the extraction is carried out in closed vessels, the temperature reached may exceed the boiling point of the solvent. In most cases, the temperature of a solvent in a container is between two to three times higher than its boiling temperature [38,39]. Solvents increase their capacity to solve analytes at higher temperatures. This is explained by the fact that the solvent surface tension and viscosity decreases as the temperature climbs, and thus its penetration into the matrix improves [40]. In recent years, the frequency of use of this technique has grown significantly, especially for the extraction of natural foods substances and metabolites from plants. Thus, it has been used for the extraction of the phenolic compounds and anthocyanins found in maqui berries [41], myrtle [42], blackberries [43], rice grains [44], etc.

Once the different extracts have been obtained, different techniques can be used to determine the amount of anthocyanins and total phenolic compounds obtained. High-performance liquid chromatography (HPLC) is a kind of liquid chromatography based on the pumping of a solvent that acts as the mobile phase at high pressure. It is often selected for its capacity to separate different compounds, even if they are not volatile or thermolabile compounds. Ultra high-performance liquid chromatography (UHPLC) is a different variety of liquid chromatography which provides a better 
resolution when working at high pressure levels. Both systems have been used to identify phenolic compounds and anthocyanins in maoluang fruits [45], primula [46], andeanfruit [47], lotus seed [48], and açai [10,49], among others.

On the other hand, ultraviolet-visible spectroscopy is an analytical technique based on the absorption and reflectance exhibited by some compounds when electromagnetic resonance is applied in the ultraviolet and visible range. This information can be used to identify some functional groups and to determine their concentration. The Folin-Ciocalteu procedure is one of the methods that are most often used to determine the total phenolic compounds concentration. It has been applied to the analysis of phenolic compounds in Cytisusvillosus [50], Cryphaeaheteromalla [51], elderberry [52], rice [53], and açai [10], among others.

The aim of this research is to design a fast and reliable method to determine anthocyanins and total phenolic compounds in a particular açai containing raw material, i.e., commercial products as well as açai residues to be used in industries and laboratories. For that purpose, a microwave-assisted extraction method has been optimized for the extraction of the anthocyanins and the total phenolic compounds that are found in lyophilized açai samples. Finally, the optimized methods were applied to different commercial açai containing products (freeze-dried açai, as well as açai juice, jam, and tablets).

\section{Materials and Methods}

\subsection{Reagents}

The methanol (MeOH) from Fisher Scientific (Loughborough, UK), and the formic acid from Panreac (Barcelona, Spain) were both HPLC grade and used for the chromatographic separation. To regulate the $\mathrm{pH}$ of the extraction solvents, "for analysis" grade hydrochloric acid from Panreac (Barcelona, Spain) was used. Ultra-pure water was obtained from a Milli-Q water purifier system from Millipore (Bedford, MA, USA).

Cyanidin chloride ( $\geq 95 \%$ pure) from Sigma-Aldrich Chemical Co. (St. Louis, MO, USA) was the standard used for anthocyanins. As far as the total phenolic compounds are concerned, Folin-Ciocalteu reagent from EMD Millipore (Darmstadt, Germany), sodium carbonate anhydrous from Panreac (Barcelona, Spain), and gallic acid pattern from Sigma-Aldrich Chemical Co. (St. Louis, MO, USA) were employed.

\subsection{Açai Samples}

In order to optimize the microwave-assisted extraction methods, a lyophilized açai (MundoArcoiris, Besalú, Girona, Spain) from ecological agriculture was used. Furthermore, different presentations of açai products (three lyophilized açai, three açai juices, an açai tablet, and an açai jam) were selected to study the applicability of the method developed in this study.

\subsection{Microwave-Assisted Extraction}

An ETHOS 1600 (Advanced Microwave Labstation, Milestone Inc., Shelton, CT, USA) equipment was used for the microwave-assisted extraction. The appropriate amount of sample $(0.5 \mathrm{~g})$ was weighed and placed into a high pressure teflon container. After that, the corresponding amount of solvent was added and covered by a teflon cap to prevent any gas leaks that may be generated during the process. Then, it was placed in the rotary carousel. The carousel was put into the extraction equipment, and a 10-min extraction program was started. The variables that had been selected to be optimized were the extraction solvent $\left(25-75 \% \mathrm{MeOH}\right.$ in water), the extraction temperature $\left(50-100{ }^{\circ} \mathrm{C}\right)$, the extraction solvent $\mathrm{pH}(2-7)$, and the sample mass $(\mathrm{g})$ : solvent volume $(\mathrm{mL})$ ratio $(0.5: 10-0.5: 20)$.

After the extractions, the samples were cooled down at room temperature. Then, the extracts were centrifuged twice for $5 \mathrm{~min}$ at $7500 \mathrm{rpm}$ (orbital radius $9.5 \mathrm{~cm}$ ). Finally, the obtained extracts were filtered through a $0.20 \mu \mathrm{m}$ nylon syringe filter (Membrane Solution, Dallas, TX, USA) prior to their chromatographic analysis. All the extractions were performed in duplicate. 


\subsection{Experimental Design Methodology}

The positive and negative effects of the extraction variables on the response within the studied range were evaluated using the Box-Behnken statistical method, where two different responses were considered: on the one hand, the total amount of anthocyanins and, on the other hand, the total phenolic compounds.

In this experimental design, four extraction variables (each variable at three levels: low, medium, and high) have been evaluated. The four experimental variables were: solvent composition (25-50-75\% methanol in water), temperature $\left(50-75-100{ }^{\circ} \mathrm{C}\right), \mathrm{pH}(2-4.5-7)$, and sample:solvent ratio $(0.5 \mathrm{~g}$ of lyophilized açai in 10-15-20 mL). These ranges were selected based on existing previous studies on the extraction of both bioactive compounds [54,55]. The experimental design of the 27 extractions in duplicate (average values), including 3 experiments at the central point, along with their respective responses (total anthocyanins and total phenolic compounds) and the predicted values, are shown in Table S1.

The total amount of anthocyanins (mg anthocyanins per $\mathrm{g}$ of sample) as determined by UHPLC was used as one of the response variables, and the total amount of phenolic compounds ( $\mathrm{mg}$ of total phenolic compounds per $g$ of sample) as determined by the Folin-Ciocalteu method was used as the other response variable.

The responses of all these extractions were entered in a second-order polynomial equation as follows:

$$
\mathrm{Y}=\beta_{0}+\beta_{1} \mathrm{X}_{1}+\beta_{2} \mathrm{X}_{2}+\beta_{3} \mathrm{X}_{3}+\beta_{4} \mathrm{X}_{4}+\beta_{12} \mathrm{X}_{1} \mathrm{X}_{2}+\beta_{13} \mathrm{X}_{1} \mathrm{X}_{3}+\beta_{14} \mathrm{X}_{1} \mathrm{X}_{4}+\beta_{23} \mathrm{X}_{2} \mathrm{X}_{3}+\beta_{24} \mathrm{X}_{2} \mathrm{X}_{4}+\beta_{34} \mathrm{X}_{3} \mathrm{X}_{4}+\beta_{11} \mathrm{X}_{1}^{2}+\beta_{22} \mathrm{X}_{2}{ }^{2}+\beta_{33} \mathrm{X}_{3}^{2}+\beta_{44} \mathrm{X}_{4}^{2}
$$

In this equation, $Y$ is the response and $\beta_{0}$ is the ordinate at the origin; $\mathrm{X}_{1}$ (percentage of $\mathrm{MeOH}$ in the extraction solvent), $X_{2}$ (temperature of extraction), $X_{3}$ ( $\mathrm{pH}$ of the extraction solvent), and $\mathrm{X}_{4}$ (sample:solvent ratio) are the independent variables; $\beta i$ are the linear coefficients; and $\beta i j$ are the cross-product coefficients and $\beta i i$ are the quadratic coefficients.

Statgraphic Centurion (version XVII) software (Statgraphics Technologies, Inc., The Plains, VA, USA) was used to estimate the effects of the variables on the final responses, the second order mathematical model, the surface graphs, the analysis of variance, as well as the optimum levels of the significant variables.

\subsection{Identification of Anthocyanins by UHPLC-QToF-MS}

Regarding the identification of anthocyanins, an ultra high-performance liquid chromatography (UHPLC) coupled to a quadrupole-time-of-flight mass spectrometry (Q-ToF-MS) (Xevo G2, Waters Corp., Milford, MA, USA) was used. The injection volume was set to $3 \mu \mathrm{L}$. The chromatographic separation was performed on a reverse-phase C18 analytical column of $2.1 \mathrm{~mm} \times 100 \mathrm{~mm}$ and a $1.7 \mu \mathrm{m}$ particle size (Acquity UHPLC BEH C18, Waters).

We employed water ( $2 \%$ formic acid) as solvent $A$ and methanol as solvent $B$ at a flow rate of $0.4 \mathrm{~mL} \mathrm{~min}^{-1}$. The applied gradient was as follows: $0 \mathrm{~min}, 15 \% \mathrm{~B} ; 3.30 \mathrm{~min}, 20 \% \mathrm{~B} ; 3.86 \mathrm{~min}, 30 \% \mathrm{~B}$; $5.05 \mathrm{~min}, 40 \% \mathrm{~B} ; 5.35 \mathrm{~min}, 55 \% \mathrm{~B} ; 5.64 \mathrm{~min}, 60 \% \mathrm{~B} ; 5.94 \mathrm{~min}, 95 \% \mathrm{~B} ; 7.50 \mathrm{~min}, 95 \% \mathrm{~B}$. The total run time was $12 \mathrm{~min}$, including $4 \mathrm{~min}$ for re-equilibration.

The analytes were determined using an electrospray source operating in positive ionization mode under the following conditions: desolvation gas flow $=700 \mathrm{~L} \mathrm{~h}^{-1}$, desolvation temperature $=500^{\circ} \mathrm{C}$, cone gas flow $=10 \mathrm{~L} \mathrm{~h}^{-1}$, source temperature $=150^{\circ} \mathrm{C}$, capillary voltage $=700 \mathrm{~V}$, cone voltage $=20 \mathrm{~V}$, and trap collision energy $=4 \mathrm{eV}$. The full-scan mode was used $(\mathrm{m} / \mathrm{z}=100-1200)$.

Masslynx software (version 4.1) was used to control the equipment and for the acquisition and treatment of the data. The anthocyanins identified in the açai extracts were: cyanidin 3-O-glucoside, cyanidin 3-O-rutinoside, peonidin 3-O-glucoside, and peonidin 3-O-rutinoside. The molecular ions $[\mathrm{M}]^{+}$for these anthocyanins showed the following $\mathrm{m} / \mathrm{z}$ ratios: cyanidin $3-O$-glucoside, $\mathrm{m} / \mathrm{z} 449$; cyanidin 3-O-rutinoside, $\mathrm{m} / \mathrm{z}$ 595; peonidin 3-O-glucoside, $\mathrm{m} / \mathrm{z} 463$; and peonidin 3-O-rutinoside, $\mathrm{m} / \mathrm{z} 609$. 


\subsection{Separation and Quantification of Anthocyanins by UHPLC-UV-vis}

As far as the anthocyanins separation and quantification are concerned, an Elite UHPLC LaChrom Ultra System (VWR Hitachi, Tokyo, Japan) consisting of an L-2200U Autosampler, an L2300 Column Oven, an L-2160U Pumps, and an L-2420U UV-vis Detector was used. For the chromatographic separation, the column oven was adjusted to $50{ }^{\circ} \mathrm{C}$. For the analysis, the UV-vis detector was set at $520 \mathrm{~nm}$. The anthocyanins were analyzed on a HaloTM C18 Hitachi LaChrom column $(100 \times 3 \mathrm{~mm}$ I.D., particle size $2.7 \mu \mathrm{m}$ ). A gradient method, using acidified water ( $5 \%$ formic acid) as solvent $A$, and methanol as solvent $\mathrm{B}$, working at a flow rate of $1.0 \mathrm{~mL} \mathrm{~min}^{-1}$, was employed for the chromatographic separation. The employed gradient was as follows: $0 \mathrm{~min}, 15 \% \mathrm{~B} ; 1.50 \mathrm{~min}, 20 \% \mathrm{~B} ; 3.30 \mathrm{~min}, 30 \% \mathrm{~B} ; 4.80 \mathrm{~min}, 40 \% \mathrm{~B}$; $5.40 \mathrm{~min}, 55 \% \mathrm{~B} ; 5.90 \mathrm{~min}, 60 \% \mathrm{~B} ; 6.60 \mathrm{~min}, 95 \% \mathrm{~B} ; 9.30 \mathrm{~min}, 95 \% \mathrm{~B} ; 10 \mathrm{~min}, 15 \% \mathrm{~B}$. A characteristic chromatogram of the separation of the anthocyanins in açai is shown in Figure 1.

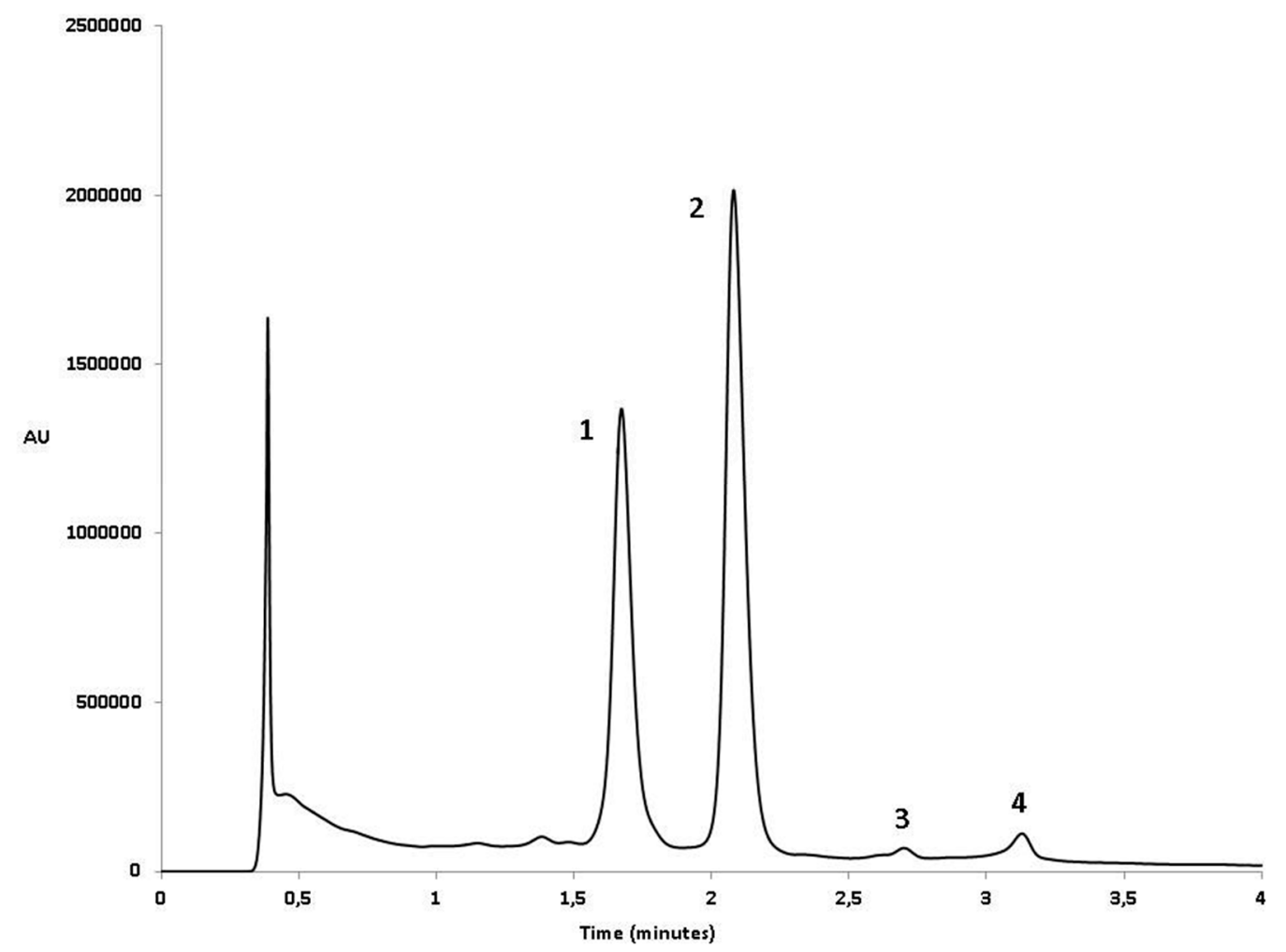

Figure 1. Chromatogram of the anthocyanins in an açai extract $(\lambda=520 \mathrm{~nm})$. (1) cyanidin 3-O-glucoside; (2) cyanidin 3-O-rutinoside; (3) peonidin 3-O-glucoside; and (4) peonidin 3-O-rutinoside.

The calibration curve of cyanidin chloride and the limits of detection (LOD) and quantification (LOQ) obtained using the UHPLC-UV-vis method were as follows: $y=300,568.88 x-28,462.43$, $\mathrm{LOD}=0.198 \mathrm{mg} \mathrm{L}^{-1}, \mathrm{LOQ}=0.662 \mathrm{mg} \mathrm{L}^{-1}$, with a linear regression coefficient $\left(\mathrm{R}^{2}\right)$ of 0.9999 . The $\mathrm{LOD}$ and LOQ were determined as the analyte concentration corresponding to the standard deviation of the signal of the blank values $(n=10)$ plus 3 or 10 times, respectively, divided by the slope of the linear regression.

The four anthocyanins present in açai (cyanidin 3-O-glucoside, cyanidin 3-O-rutinoside, peonidin 3-O-glucoside, and peonidin 3-O-rutinoside) were quantified using the calibration curve for cyanidin chloride, taking into account the molecular weight of the anthocyanins analyzed. All the analyses were carried out in triplicate.

\subsection{Total Phenolic Content}

The total phenolic content of the extracts obtained from açai, both in the experimental design and in subsequent assays, was determined through the spectrophotometric Folin-Ciocalteu method 
described by Singleton and Rossi [56], incorporating the modifications suggested by Singleton et al. [57] for vegetable extracts. Gallic acid was used as the standard. A methanolic solution of gallic acid (1000 $\left.\mathrm{mg} \mathrm{L}^{-1}\right)$ was diluted in methanol at various concentrations $\left(0.1-500 \mathrm{mg} \mathrm{L}^{-1}\right)$ to produce the standard curve. The reaction was performed by transferring $0.25 \mathrm{~mL}$ of standard solution or extract samples into $25 \mathrm{~mL}$ volumetric flasks. Then, $12.5 \mathrm{~mL}$ of distilled water, $1.25 \mathrm{~mL}$ of Folin-Ciocalteu reagent, and $5 \mathrm{~mL}$ of aqueous sodium carbonate solution $20 \%(\mathrm{w} / \mathrm{v})$ were added in this order. After that, the volumetric flask was flushed with distilled water and was manually stirred for $30 \mathrm{~s}$ and kept protected from the light at room temperature for $30 \mathrm{~min}$. The absorbance of the solution was measured at $765 \mathrm{~nm}$ by means of a spectrophotometer (JASCO V-530, JASCO Corporation, Tokyo, Japan) with a quartz cuvette of $10 \mathrm{~mm}$ path length.

The calibration curve obtained for the gallic acid standard was $y=0.0024 x-0.0031$. The analytical parameters of the calibration were: $R^{2}=0.9999$; $\mathrm{LOD}=1.649 \mathrm{mg} \mathrm{L}^{-1} ; \mathrm{LOQ}=5.498 \mathrm{mg} \mathrm{L}^{-1}$.

\section{Results}

\subsection{Box-Behnken Design}

A Box-Behnken design was used to optimize the extraction conditions for the total anthocyanins and total phenolic compounds from freeze-dried açai. Four different extraction variables were studied in the following ranges: \% methanol in water between $25 \%$ and $75 \%$, temperature values between 50 and $100{ }^{\circ} \mathrm{C}$, solvent $\mathrm{pH}$ between 2 and 7, and sample-to-solvent ratio between 0.5:10 and 0.5:20 g açai: $\mathrm{mL}$ of extraction solvent. A total of 27 extractions in duplicate were performed. The extraction time was initially fixed at $10 \mathrm{~min}$, and the amount of lyophilized açai employed was $0.5 \mathrm{~g}$. All the experiments were performed in duplicate, and they are presented in Table S1.

\subsection{Anthocyanins Optimization}

\subsubsection{Optimization of the Extraction Method}

Once the 27 extractions were carried out by duplicate, the anthocyanin content in the extracts was quantified by UHPLC-UV-vis. The individual anthocyanins were added together to determine the total anthocyanins. The Box-Behnken design was applied to those values (average of each duplicate analysis) to determine the most influential variables and the optimum conditions for the extraction of the anthocyanins in açai.

The predicted values obtained from Equation (1) were correlated with the real values of the total anthocyanins. The data related to the fitting properties of the resulting model, expressed as a percentage of the differences between the experimental values for the anthocyanin recoveries and the calculated ones, are presented in Table S1.

The resulting average difference between the experimental data and the calculated values was $2.33 \%$, ranging from $0.00 \%$ to $20.49 \%$. This means that the extraction variables control the final extract composition in terms of anthocyanins recovery and that the extraction conditions can therefore be adjusted to optimize the extraction of the anthocyanins present in açai.

The standardized Pareto chart (Figure 2) and the $p$-values (Table 1) show that the most influential variables for the extraction of total anthocyanins in açai were the percentage of methanol in the extraction solvent ( $p$-value: 0.000$)$, the quadratic interaction of the percentage of methanol ( $p$-value: $0.000)$, the interaction temperature-pH ( $p$-value: 0.0154$)$, and the interaction $\mathrm{pH}$-ratio ( $p$-value: 0.000$)$. 


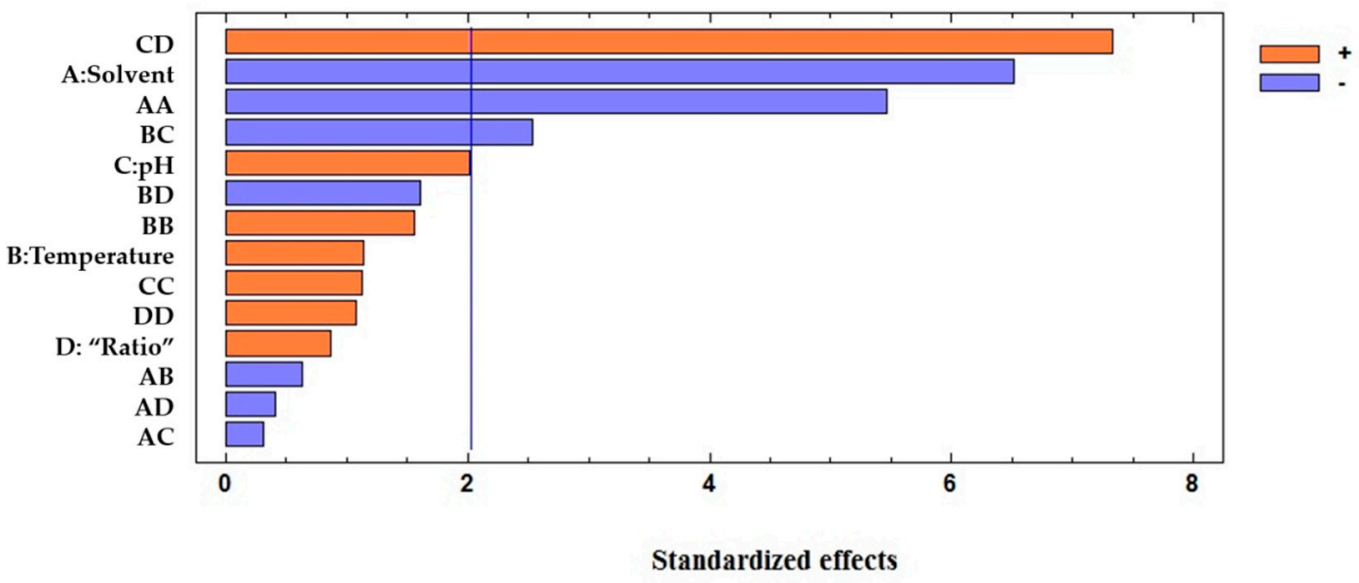

Figure 2. The obtained standardized Pareto chart representing the optimization of the total anthocyanins extraction.

Table 1. Coefficients of the second-order polynomial equation obtained using the Box-Behnken design.

\begin{tabular}{ccccc}
\hline & $\begin{array}{c}\text { Total } \\
\text { Anthocyanins } \\
\text { Coefficients }\end{array}$ & $\begin{array}{c}\text { Total } \\
\text { Anthocyanins } \\
p \text {-Values }\end{array}$ & $\begin{array}{c}\text { Total Phenolic } \\
\text { Compounds } \\
\text { Coefficients }\end{array}$ & $\begin{array}{c}\text { Total Phenolic } \\
\text { Compounds } \\
p \text {-Values }\end{array}$ \\
\hline$\beta_{0}$ & 1.1677 & & 12.1491 & \\
Solvent & -0.2796 & 0.0000 & 0.0910 & 0.7219 \\
Temperature & 0.0366 & 0.2743 & 0.5627 & 0.0055 \\
pH & 0.0863 & 0.0513 & 0.1178 & 0.6452 \\
"Ratio" & 0.0373 & 0.3895 & 0.1233 & 0.6298 \\
Solvent:Solvent & -0.2944 & 0.0000 & 0.0197 & 0.9511 \\
Solvent:Temperature & -0.0297 & 0.5310 & -0.0372 & 0.8942 \\
Solvent:pH & -0.0195 & 0.7560 & -0.4179 & 0.2630 \\
Solvent:"Ratio" & -0.0254 & 0.6849 & 0.2586 & 0.4863 \\
Temperature:Temperature 0.0937 & 0.1276 & 0.0745 & 0.8355 \\
Temperature:pH & -0.1190 & 0.0154 & -0.2429 & 0.3878 \\
Temperature:"Ratio" & -0.0753 & 0.1170 & 0.2577 & 0.3598 \\
pH:pH & 0.0606 & 0.2671 & -0.6920 & 0.0360 \\
pH:"Ratio" & 0.4560 & 0.0000 & 1.3633 & 0.0007 \\
"Ratio":"Ratio" & 0.0580 & 0.2879 & -0.3455 & 0.2849 \\
\hline
\end{tabular}

It was expected that the percentage of methanol in the solvent extraction would be one of the most influential factors regarding the extraction of anthocyanins, since an extraction of this kind of compounds requires a solvent or a mix of solvents with a similar polarity to the compounds of interest. As expected, the quadratic interaction of the percentage of methanol and the individual effect of the percentage of methanol were the most influential factors. $38.23 \%$ methanol in water was the optimum value for the extraction of anthocyanins. This value is in accordance with the solvents used to extract these kinds of compounds from other vegetables matrixes such as blackberry [58], black bamboo [59], etc. The interaction between the $\mathrm{pH}$ and the ratio of solvent employed had a smaller influence on the extraction of total anthocyanins. The optimum values for the extraction of anthocyanins are shown in Table 2.

\subsubsection{Kinetics of the Extraction Process}

To assess the kinetics of the extraction process, three different extractions were carried out under the optimum conditions using different extraction times $(2,5,10,15,20$, and $25 \mathrm{~min})$. It can be observed from Figure 3 that the optimum time for the extraction, i.e., when the maximum recovery of anthocyanins is obtained, was $10 \mathrm{~min}$. In fact, longer extraction periods affect the anthocyanins recovery, likely due to the degradation of these compounds because of the temperature [60]. 
Table 2. The optimum conditions from MAE for anthocyanins and total phenolic compounds.

\begin{tabular}{ccc}
\hline Variable & $\begin{array}{c}\text { Optimum Values for } \\
\text { Total Anthocyanins }\end{array}$ & $\begin{array}{c}\text { Optimum Values for Total } \\
\text { Phenolic Compounds }\end{array}$ \\
\hline Solvent $(\% \mathrm{MeOH})$ & 38.23 & 74.16 \\
Temperature $\left({ }^{\circ} \mathrm{C}\right)$ & 99.63 & 99.14 \\
$\mathrm{pH}$ & 2.00 & 5.46 \\
"Ratio" $(\mathrm{mL})$ & 10 & 20 \\
\hline
\end{tabular}

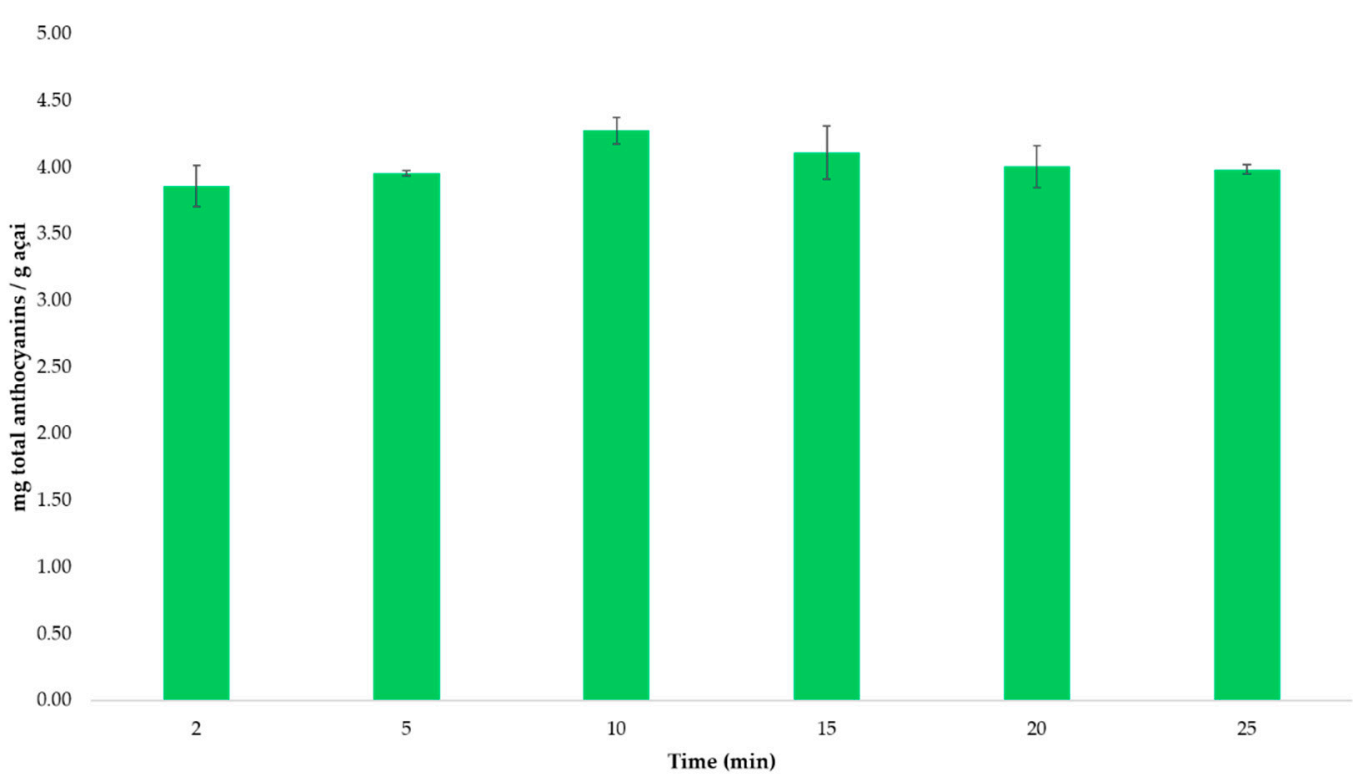

Figure 3. Milligrams of total anthocyanins recovered per gram of açai at different extraction times $(n=3)$.

\subsubsection{Repeatability and Intermediate Precision of the Method}

The repeatability and intermediate precision of the developed method have been determined. For this purpose, a total of 30 extractions were performed, distributed as follows: 12 extractions performed on the first day of the study, and 9 more extractions on each of the two subsequent days. It can be observed in Table 3 that the method had a suitable repeatability (RSD 1.66\%) and intermediate precision (RSD 3.23\%).

Table 3. The results obtained from the repeatability and intermediate precision study for anthocyanins and total phenolic compounds.

\begin{tabular}{ccc}
\hline & Repeatability $^{\mathbf{1}}$ & Intermediate Precision $^{\mathbf{2}}$ \\
\hline Average (mg total anthocyanins/g açai) & 4.377 & 4.346 \\
Standard deviation & 0.073 & 0.140 \\
Relative standard deviation (\%) & 1.66 & 3.23 \\
\hline Average (mg total phenolics/g açai) & 10.523 & 10.574 \\
Standard deviation & 0.228 & 0.256 \\
Relative standard deviation (\%) & 2.17 & 2.42 \\
\hline
\end{tabular}

${ }^{1}$ Repeatability $(n=12) ;{ }^{2}$ Intermediate precision $(n=27)$.

\subsection{Phenolic Compounds Optimization}

\subsubsection{Optimization of the Extraction Method}

The same extraction experiments that were carried out to determine the best conditions for the extraction of total anthocyanins using the Box-Behnken design were applied to the optimization of the 
total phenolic compounds extraction method. In this case, the Folin-Ciocalteu method described above was used to measure the total phenolic compounds in the extracts. With these values (average of each duplicate analysis), the Box-Behnken design was applied to determine the most influential variables and the optimum conditions for the extraction of total phenolic compounds.

The real values of the total phenolic compounds were correlated with the predicted values obtained by Equation (1). The actual values and predicted values, and the differences between them (\%), are presented in Table S1. The resulting average difference ranged between $0.35 \%$ and $18.85 \%$, and its average was $5.61 \%$. This means that the extraction variables that were managed during the experiment control the final extract composition in terms of total phenolic compounds recovery and that the extraction conditions can therefore be adjusted to optimize the extraction of the phenolic compounds present in açai.

The standardized Pareto chart (Figure 4) and the $p$-values table (Table 1) showed that the most influential factors in the extraction of total phenolic compounds in açai were the temperature ( $p$-value: 0.0055$)$, the quadratic relation $\mathrm{pH}-\mathrm{pH}$ ( $p$-value: 0.0360$)$, and the interaction $\mathrm{pH}$-"ratio" ( $p$-value: 0.0007$)$.

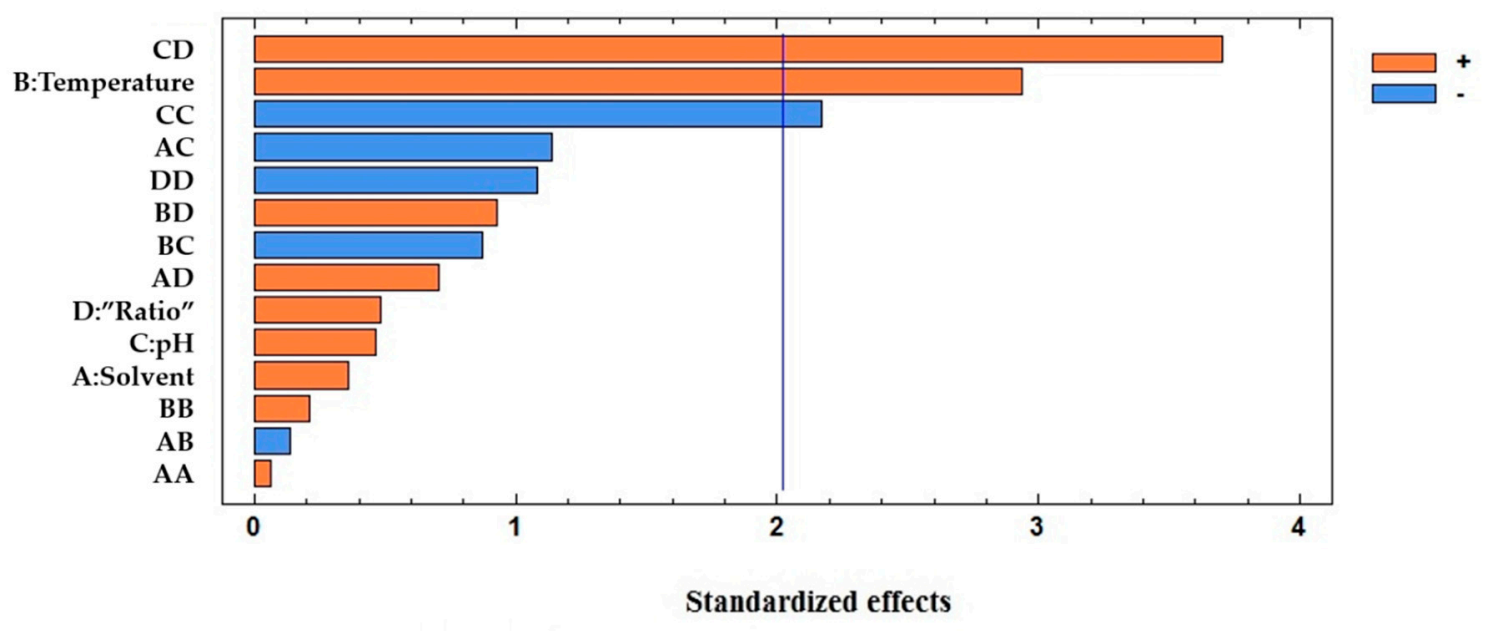

Figure 4. The obtained standardized Pareto chart representing the optimization of total phenolic compounds extraction.

Unlike what happened with total anthocyanins, the percentage of methanol did not represent an important influence on the amount of total phenolic compounds extracted. Phenolic compounds have a high range of polarity; thus, there is not a specific percentage of methanol that suits the extraction requirements of these compounds [61]. Consequently, the methanol percentage has a minor influence on the amount of phenolic compounds extracted. However, in this case, the temperature is a highly influential factor as it improves the extraction kinetics of these kinds of compounds; higher temperatures facilitate the solubility of the compounds and, as a consequence, their extraction [62]. Other factors, such as the volume of solvent employed, also have a remarkable effect. The optimum values for the total phenolic compounds extraction were gathered in Table 3.

\subsubsection{Kinetics of the Extraction Process}

The kinetics of the extraction of total phenolic compounds were also studied. In order to study the kinetics of the extraction process, three experiments at optimum extraction conditions (Table 2) were carried out using different extraction times (between 2 and $25 \mathrm{~min}$ ). The results for the recovery of total phenolic compounds are represented in Figure 5. As in the case of anthocyanins, the optimum extraction time for the total phenolic compounds was $10 \mathrm{~min}$, although no significant differences between 10 and 15 min could be observed. 


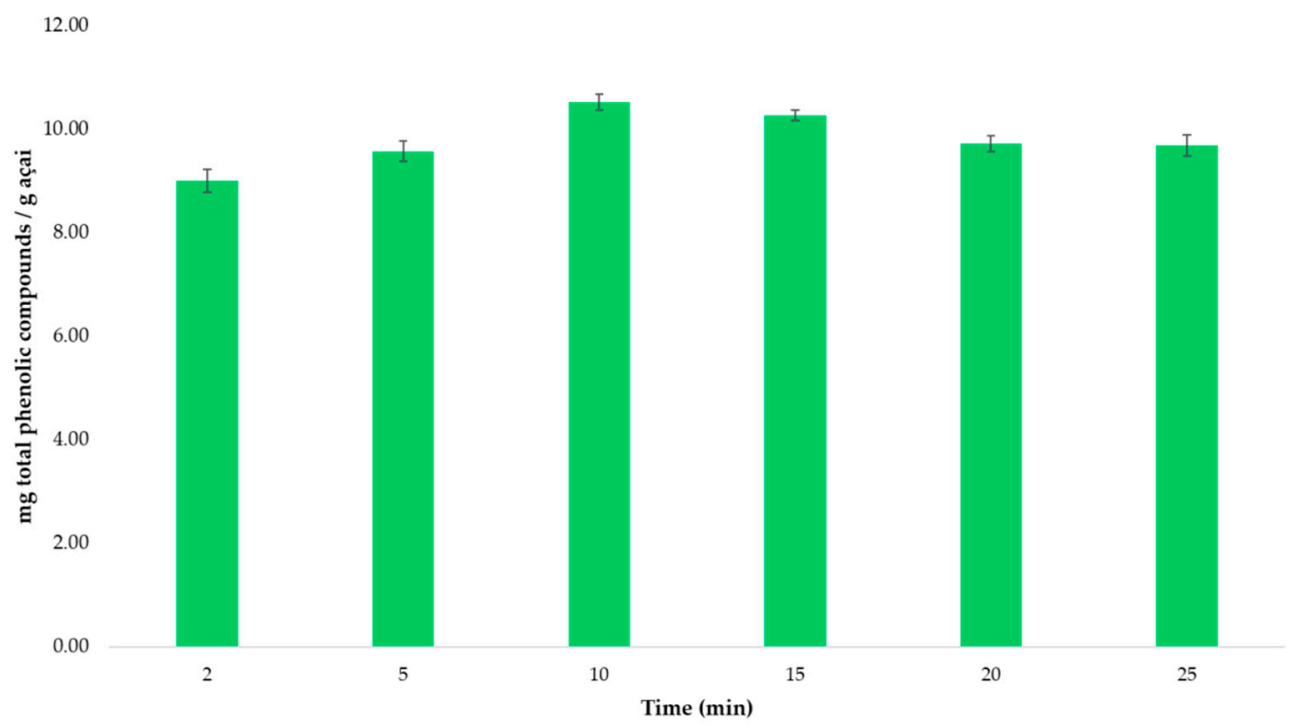

Figure 5. Milligrams of total phenolic compounds recovered per gram of açai recoveries during the kinetics study.

\subsubsection{Repeatability and Intermediate Precision of the Method}

The repeatability and intermediate precision of the method were determined by means of different extractions in three consecutive days under the optimum extraction conditions that had been previously determined. 12 extractions were carried out on the same day to determine the repeatability. 9 additional extractions were performed on each one of the two consecutive days. The results (Table 3 ) showed the excellent repeatability (RSD 2.17\%) and intermediate precision (RSD 2.42\%) of the method.

\subsection{Re-Extraction Experiments}

A re-extraction study of the sample was carried out after the extraction, using the optimal extraction conditions for both total phenolic compounds and total anthocyanins. Quantities under 5\% of the total phenolic compounds and total anthocyanins were obtained in both cases.

\subsection{Application of the Methods to Real Samples}

Once the two methods were developed and optimized for the microwave-assisted extraction of anthocyanins and phenolic compounds from açai, they were applied to eight real samples to demonstrate their suitability.

The extraction results are presented in Table 4, where large amounts of phenolic compounds can be observed. The largest amount of phenolic compounds was obtained from lyophilized açai, but the rest of the samples also had a high concentration of phenolic compound, ranging between 1.42 and $12.37 \mathrm{mg}$ of the total phenolic compounds per gram of açai.

Table 4. The amount of total anthocyanins and total phenolic compounds in real açai samples.

\begin{tabular}{ccc}
\hline Samples & mg Total Anthocyanins/g sample & $\begin{array}{c}\text { mg Total Phenolic } \\
\text { Compounds/g sample }\end{array}$ \\
\hline Freeze-dried açai (1) & $5.56 \pm 0.34$ & $12.37 \pm 0.49$ \\
Freeze-dried açai (2) & $4.47 \pm 0.41$ & $10.61 \pm 0.37$ \\
Freeze-dried açai (3) & $4.05 \pm 0.25$ & $9.67 \pm 0.50$ \\
Açai juice & $0.04 \pm 0.00$ & $2.48 \pm 0.22$ \\
Açai juice food supplement & $0.05 \pm 0.00$ & $2.53 \pm 0.18$ \\
Concentrated juice açai-banana & $0.01 \pm 0.00$ & $5.15 \pm 0.29$ \\
Açai tablet & $0.04 \pm 0.00$ & $2.17 \pm 0.25$ \\
Açai jam & $0.14 \pm 0.01$ & $1.42 \pm 0.08$ \\
\hline
\end{tabular}


On the other hand, the concentration levels of anthocyanins in the real samples, except for the lyophilized açai ones, were very low. This is most probably due to the degradation of anthocyanins during the manufacturing process or storage of açai products [32]. Another possible reason is the small amount of açai used for the manufacturing of these products or the addition by manufacturers of other more affordable purple fruits to obtain a color similar to that of real açai. This theory is supported by the fact that some of the obtained chromatograms showed a series of peaks with retention times of over four minutes, probably caused by the presence of anthocyanins from different berries other than açai.

\section{Conclusions}

In the present work, four different anthocyanins were identified in açai: cyanidin 3-O-glucoside, cyanidin 3-O-rutinoside, peonidin 3-O-glucoside, and peonidin 3-O-rutinoside.

Two methods, where microwaves assisted the extraction of both the anthocyanins and the total phenolic compounds present in açai, were optimized. On the one hand, the optimum conditions for the extraction of anthocyanins were determined as follows: $38.23 \% \mathrm{MeOH}$ in the extraction solvent, $99.63{ }^{\circ} \mathrm{C}, \mathrm{pH} 2$, and 0.5:10 g açai: $\mathrm{mL}$ of extraction solvent ratio. On the other hand, the optimum conditions for the extraction of the phenolic compounds were determined as follows: $74.16 \% \mathrm{MeOH}$ in the extraction solvent, $99.14^{\circ} \mathrm{C}, \mathrm{pH} 5.46$, and $0.5: 20 \mathrm{~mL}$ g açai: $\mathrm{mL}$ of extraction solvent ratio. Both methods exhibited both a high repeatability and intermediate precision, with RSD values below $3 \%$ in all cases.

A kinetics study was carried out, and 10 min of extraction time was proven to be enough to obtain the maximum amount of both total anthocyanins and total phenolic compounds. Both methods have proven their reliability and rapid implementation, and could therefore be considered as being perfectly suitable to implementation on an industrial scale.

Supplementary Materials: The following are available online at http://www.mdpi.com/2073-4395/10/2/179/s1, Table S1. Box-Behnken design matrix with the values of the six variables for each experiment and measured and predicted responses $(n=2)$.

Author Contributions: Conceptualization, E.E.-B. and G.F.B.; methodology, E.E.-B. and G.F.B.; software, M.F.-G.; formal analysis, M.J.A.-G. and C.C.; investigation, E.E.-B., C.C. and G.F.B.; resources, J.Á.Á., M.P. and J.A.; data curation, M.J.A.-G., M.F.-G. and G.F.B.; writing—original draft preparation, M.J.A.-G.; writing-review and editing, G.F.B., M.F.-G. and E.E.-B.; supervision, G.F.B., M.F.-G. and E.E.-B.; project administration, G.F.B., J.Á.Á., M.P. and J.A. All authors have read and agreed to the published version of the manuscript.

Funding: The authors acknowledge V. la Andaluza and University of Cadiz for the support provided through the project OT2016/046.

Acknowledgments: The authors are grateful to the Instituto de Investigación Vitivinícola y Agroalimentaria (IVAGRO) for providing the necessary facilities to carry out the research and Programa de Fomento e Impulso de la Actividad de Investigación y Transferencia de la Universidad de Cádiz for the payment support of this manuscript.

Conflicts of Interest: The authors declare no conflict of interest.

\section{References}

1. Ye, D.; Jiang, Z.; Zheng, F.; Wang, H.; Zhang, Y.; Gao, F.; Chen, P.; Chen, Y.; Shi, G. Optimized Extraction of Polysaccharides from Grateloupia livida (Harv.) Yamada and Biological Activities. Molecules 2015, 20, 16817-16832. [CrossRef] [PubMed]

2. Munro, B.; Vuong, Q.; Chalmers, A.; Goldsmith, C.; Bowyer, M.; Scarlett, C. Phytochemical, Antioxidant and Anti-Cancer Properties of Euphorbia tirucalli Methanolic and Aqueous Extracts. Antioxidants 2015, 4, 647-661. [CrossRef] [PubMed]

3. Velderrain-Rodríguez, G.; Torres-Moreno, H.; Villegas-Ochoa, M.; Ayala-Zavala, J.; Robles-Zepeda, R.; Wall-Medrano, A.; González-Aguilar, G. Gallic Acid Content and an Antioxidant Mechanism Are Responsible for the Antiproliferative Activity of 'Ataulfo' Mango Peel on LS180 Cells. Molecules 2018, 23, 695. [CrossRef] [PubMed] 
4. Bogusz, S.; Libardi, S.H.; Dias, F.F.; Coutinho, J.P.; Bochi, V.C.; Rodrigues, D.; Melo, A.M.; Godoy, H.T. Brazilian Capsicum peppers: Capsaicinoid content and antioxidant activity. J. Sci. Food Agric. 2018, 98, 217-224. [CrossRef] [PubMed]

5. Gironés-Vilaplana, A.; Valentão, P.; Moreno, D.A.; Ferreres, F.; García-Viguera, C.; Andrade, P.B. New Beverages of Lemon Juice Enriched with the Exotic Berries Maqui, Açaí, and Blackthorn: Bioactive Components and in Vitro Biological Properties. J. Agric. Food Chem. 2012, 60, 6571-6580. [CrossRef] [PubMed]

6. Kang, J.; Thakali, K.M.; Xie, C.; Kondo, M.; Tong, Y.; Ou, B.; Jensen, G.; Medina, M.B.; Schauss, A.G.; Wu, X. Bioactivities of açaí (Euterpe precatoria Mart.) fruit pulp, superior antioxidant and anti-inflammatory properties to Euterpe oleracea Mart. Food Chem. 2012, 133, 671-677. [CrossRef]

7. Gordon, A.; Cruz, A.P.G.; Cabral, L.M.C.; de Freitas, S.C.; Taxi, C.M.A.D.; Donangelo, C.M.; de Andrade Mattietto, R.; Friedrich, M.; da Matta, V.M.; Marx, F. Chemical characterization and evaluation of antioxidant properties of Açaí fruits (Euterpe oleraceae Mart.) during ripening. Food Chem. 2012, 133, 256-263. [CrossRef]

8. Kang, J.; Xie, C.; Li, Z.; Nagarajan, S.; Schauss, A.G.; Wu, T.; Wu, X. Flavonoids from acai (Euterpe oleracea Mart.) pulp and their antioxidant and anti-inflammatory activities. Food Chem. 2011, 128, 152-157. [CrossRef]

9. Lucas, B.F.; Zambiazi, R.C.; Costa, J.A.V. Biocompounds and physical properties of açaí pulp dried by different methods. LWT-Food Sci. Technol. 2018, 98, 335-340. [CrossRef]

10. Hogan, S.; Chung, H.; Zhang, L.; Li, J.; Lee, Y.; Dai, Y.; Zhou, K. Antiproliferative and antioxidant properties of Anthocyanin-rich extract from açai. Food Chem. 2010, 118, 208-214. [CrossRef]

11. López de Dicastillo, C.; Piña, C.; Garrido, L.; Arancibia, C.; Galotto, M.J. Enhancing Thermal Stability and Bioaccesibility of Açaí Fruit Polyphenols through Electrohydrodynamic Encapsulation into Zein Electrosprayed Particles. Antioxidants 2019, 8, 464. [CrossRef] [PubMed]

12. Censi, R.; Vargas Peregrina, D.; Lacava, G.; Agas, D.; Lupidi, G.; Sabbieti, M.; Di Martino, P. Cosmetic Formulation Based on an Açai Extract. Cosmetics 2018, 5, 48. [CrossRef]

13. Poulose, S.M.; Fisher, D.R.; Larson, J.; Bielinski, D.F.; Rimando, A.M.; Carey, A.N.; Schauss, A.G.; Shukitt-Hale, B. Anthocyanin-rich Açai (Euterpe oleracea Mart.) Fruit Pulp Fractions Attenuate Inflammatory Stress Signaling in Mouse Brain BV-2 Microglial Cells. J. Agric. Food Chem. 2012, 60, 1084-1093. [CrossRef] [PubMed]

14. Martinez, R.; Guimarães, D.; Berniz, C.; Abreu, J.; Rocha, A.; Moura, R.; Resende, A.; Teodoro, A. Açai (Euterpe oleracea Mart.) Seed Extract Induces Cell Cycle Arrest and Apoptosis in Human Lung Carcinoma Cells. Foods 2018, 7, 178. [CrossRef]

15. Pacheco-Palencia, L.A.; Mertens-Talcott, S.U.; Talcott, S.T. In vitro absorption and antiproliferative activities of monomeric and polymeric Anthocyanin fractions from açai fruit (Euterpe oleracea Mart.). Food Chem. 2010, 119, 1071-1078. [CrossRef]

16. Del Pozo-Insfran, D.; Percival, S.S.; Talcott, S.T. Açai ( Euterpe oleracea Mart.) Polyphenolics in Their Glycoside and Aglycone Forms Induce Apoptosis of HL-60 Leukemia Cells. J. Agric. Food Chem. 2006, 54, 1222-1229. [CrossRef]

17. Brunschwig, C.; Leba, L.-J.; Saout, M.; Martial, K.; Bereau, D.; Robinson, J.-C. Chemical Composition and Antioxidant Activity of Euterpe oleracea Roots and Leaflets. Int. J. Mol. Sci. 2016, 18, 61. [CrossRef]

18. de Moura, R.S.; Ferreira, T.S.; Lopes, A.A.; Pires, K.M.P.; Nesi, R.T.; Resende, A.C.; Souza, P.J.C.; da Silva, A.J.R.; Borges, R.M.; Porto, L.C.; et al. Effects of Euterpe oleracea Mart. (AÇAÍ) extract in acute lung inflammation induced by cigarette smoke in the mouse. Phytomedicine 2012, 19, 262-269. [CrossRef]

19. Wang, L.-S.; Stoner, G.D. Anthocyanins and their role in cancer prevention. Cancer Lett. 2008, 269, $281-290$. [CrossRef]

20. V. González de Peredo, A.; Vázquez-Espinosa, M.; Espada-Bellido, E.; Ferreiro-González, M.; Amores-Arrocha, A.; Palma, M.; Barbero, G.F.; Jiménez-Cantizano, A. Alternative Ultrasound-Assisted Method for the Extraction of the Bioactive Compounds Present in Myrtle (Myrtus communis L.). Molecules 2019, 24, 882. [CrossRef]

21. Vázquez-Espinosa, M.; V. González-de-Peredo, A.; Espada-Bellido, E.; Ferreiro-González, M.; Toledo-Domínguez, J.J.; Carrera, C.; Palma, M.; Barbero, G.F. Ultrasound-Assisted Extraction of Two Types of Antioxidant Compounds (TPC and TA) from Black Chokeberry (Aronia melanocarpa L.): Optimization of the Individual and Simultaneous Extraction Methods. Agronomy 2019, 9, 456. [CrossRef] 
22. Gallori, S.; Bilia, A.R.; Bergonzi, M.C.; Barbosa, W.L.R.; Vincieri, F.F. Polyphenolic Constituents of Fruit Pulp of Euterpe oleracea Mart. (Açai palm). Chromatographia 2004, 59. [CrossRef]

23. Pacheco-Palencia, L.A.; Talcott, S.T. Chemical stability of açai fruit (Euterpe oleracea Mart.) Anthocyanins as influenced by naturally occurring and externally added polyphenolic cofactors in model systems. Food Chem. 2010, 118, 17-25. [CrossRef]

24. Mazewski, C.; Liang, K.; Gonzalez de Mejia, E. Inhibitory potential of Anthocyanin-rich purple and red corn extracts on human colorectal cancer cell proliferation in vitro. J. Funct. Foods 2017, 34, 254-265. [CrossRef]

25. Long, H.-L.; Zhang, F.-F.; Wang, H.-L.; Yang, W.-S.; Hou, H.-T.; Yu, J.-K.; Liu, B. Mulberry Anthocyanins improves thyroid cancer progression mainly by inducing apoptosis and autophagy cell death. Kaohsiung J. Med. Sci. 2018, 34, 255-262. [CrossRef]

26. Zhou, L.; Wang, H.; Yi, J.; Yang, B.; Li, M.; He, D.; Yang, W.; Zhang, Y.; Ni, H. Anti-tumor properties of Anthocyanins from Lonicera caerulea 'Beilei' fruit on human hepatocellular carcinoma: In vitro and in vivo study. Biomed. Pharmacother. 2018, 104, 520-529. [CrossRef]

27. Phan, M.A.T.; Bucknall, M.; Arcot, J. Interactive effects of $\beta$-carotene and Anthocyanins on cellular uptake, antioxidant activity and anti-inflammatory activity in vitro and ex vivo. J. Funct. Foods 2018, 45, 129-137. [CrossRef]

28. Rogez, H.; Pompeu, D.R.; Akwie, S.N.T.; Larondelle, Y. Sigmoidal kinetics of Anthocyanin accumulation during fruit ripening: A comparison between açai fruits (Euterpe oleracea) and other Anthocyanin-rich fruits. J. Food Compos. Anal. 2011, 24, 796-800. [CrossRef]

29. Seeram, N.P.; Nair, M.G. Inhibition of Lipid Peroxidation and Structure-Activity-Related Studies of the Dietary Constituents Anthocyanins, Anthocyanidins, and Catechins. J. Agric. Food Chem. 2002, 50, 5308-5312. [CrossRef]

30. Sandoval, V.; Femenias, A.; Martínez-Garza, Ú.; Sanz-Lamora, H.; Castagnini, J.; Quifer-Rada, P.; Lamuela-Raventós, R.; Marrero, P.; Haro, D.; Relat, J. Lyophilized Maqui (Aristotelia chilensis) Berry Induces Browning in the Subcutaneous White Adipose Tissue and Ameliorates the Insulin Resistance in High Fat Diet-Induced Obese Mice. Antioxidants 2019, 8, 360. [CrossRef]

31. Parra-Galindo, M.-A.; Piñeros-Niño, C.; Soto-Sedano, J.C.; Mosquera-Vasquez, T. Chromosomes I and X Harbor Consistent Genetic Factors Associated with the Anthocyanin Variation in Potato. Agronomy 2019, 9, 366. [CrossRef]

32. Kang, J.; Li, Z.; Wu, T.; Jensen, G.S.; Schauss, A.G.; Wu, X. Anti-oxidant capacities of flavonoid compounds isolated from acai pulp (Euterpe oleracea Mart.). Food Chem. 2010, 122, 610-617. [CrossRef]

33. de Cássia Rodrigues Batista, C.; de Oliveira, M.S.; Araújo, M.E.; Rodrigues, A.M.C.; Botelho, J.R.S.; da Silva Souza Filho, A.P.; Machado, N.T.; Carvalho, R.N. Supercritical $\mathrm{CO}_{2}$ extraction of açaí (Euterpe oleracea) berry oil: Global yield, fatty acids, allelopathic activities, and determination of phenolic and Anthocyanins total compounds in the residual pulp. J. Supercrit. Fluids 2016, 107, 364-369. [CrossRef]

34. Oliveira, A.F.A.; Mar, J.M.; Santos, S.F.; da Silva Júnior, J.L.; Kluczkovski, A.M.; Bakry, A.M.; de Bezerra, J.A.; de Nunomura, R.C.S.; Sanches, E.A.; Campelo, P.H. Non-thermal combined treatments in the processing of açai (Euterpe oleracea) juice. Food Chem. 2018, 265, 57-63. [CrossRef] [PubMed]

35. Vieira, G.S.; Cavalcanti, R.N.; Meireles, M.A.A.; Hubinger, M.D. Chemical and economic evaluation of natural antioxidant extracts obtained by ultrasound-assisted and agitated bed extraction from jussara pulp (Euterpe edulis). J. Food Eng. 2013, 119, 196-204. [CrossRef]

36. Einaga, H.; Nasu, Y.; Oda, M.; Saito, H. Catalytic performances of perovskite oxides for CO oxidation under microwave irradiation. Chem. Eng. J. 2016, 283, 97-104. [CrossRef]

37. Li, Y.; Han, L.; Ma, R.; Xu, X.; Zhao, C.; Wang, Z.; Chen, F.; Hu, X. Effect of energy density and citric acid concentration on Anthocyanins yield and solution temperature of grape peel in microwave-assisted extraction process. J. Food Eng. 2012, 109, 274-280. [CrossRef]

38. Kapoore, R.; Butler, T.; Pandhal, J.; Vaidyanathan, S. Microwave-Assisted Extraction for Microalgae: From Biofuels to Biorefinery. Biology 2018, 7, 18. [CrossRef]

39. Moret, S.; Conchione, C.; Srbinovska, A.; Lucci, P. Microwave-Based Technique for Fast and Reliable Extraction of Organic Contaminants from Food, with a Special Focus on Hydrocarbon Contaminants. Foods 2019, 8, 503. [CrossRef] 
40. Garcia-Salas, P.; Morales-Soto, A.; Segura-Carretero, A.; Fernández-Gutiérrez, A. Phenolic-Compound-Extraction Systems for Fruit and Vegetable Samples. Molecules 2010, 15, 8813-8826. [CrossRef]

41. Vázquez-Espinosa, M.; V. González de Peredo, A.; Ferreiro-González, M.; Carrera, C.; Palma, M.; Barbero, G.F.; Espada-Bellido, E. Assessment of Ultrasound Assisted Extraction as an Alternative Method for the Extraction of Anthocyanins and Total Phenolic Compounds from Maqui Berries (Aristotelia chilensis (Mol.) Stuntz). Agronomy 2019, 9, 148. [CrossRef]

42. V. González de Peredo, A.; Vázquez-Espinosa, M.; Espada-Bellido, E.; Jiménez-Cantizano, A.; Ferreiro-González, M.; Amores-Arrocha, A.; Palma, M.; Barroso, C.G.; Barbero, G.F. Development of New Analytical Microwave-Assisted Extraction Methods for Bioactive Compounds from Myrtle (Myrtus communis L.). Molecules 2018, 23, 2992. [CrossRef]

43. Espada-Bellido, E.; Ferreiro-González, M.; Carrera, C.; Palma, M.; Álvarez, J.A.; Barbero, G.F.; Ayuso, J. Extraction of Antioxidants from Blackberry (Rubus ulmifolius L.): Comparison between Ultrasound- and Microwave-Assisted Extraction Techniques. Agronomy 2019, 9, 745. [CrossRef]

44. Setyaningsih, W.; Saputro, I.E.; Palma, M.; Barroso, C.G. Optimisation and validation of the microwave-assisted extraction of phenolic compounds from rice grains. Food Chem. 2015, 169, 141-149. [CrossRef] [PubMed]

45. Krongyut, O.; Sutthanut, K. Phenolic Profile, Antioxidant Activity, and Anti-obesogenic Bioactivity of Mao Luang Fruits (Antidesma bunius L.). Molecules 2019, 24, 4109. [CrossRef] [PubMed]

46. Tarapatskyy, M.; Kapusta, I.; Gumienna, A.; Puchalski, C. Assessment of the Bioactive Compounds in White and Red Wines Enriched with a Primula veris L. Molecules 2019, 24, 4074. [CrossRef]

47. Jiménez-Aspee, F.; Theoduloz, C.; Pormetter, L.; Mettke, J.; Ávila, F.; Schmeda-Hirschmann, G. Andean Prumnopitys Andina (Podocarpacae) Fruit Extracts: Characterization of Secondary Metabolites and Potential Cytoprotective Effect. Molecules 2019, 24, 4028. [CrossRef]

48. Ma, Z.; Huang, Y.; Huang, W.; Feng, X.; Yang, F.; Li, D. Separation, Identification, and Antioxidant Activity of Polyphenols from Lotus Seed Epicarp. Molecules 2019, 24, 4007. [CrossRef]

49. Bataglion, G.A.; da Silva, F.M.A.; Eberlin, M.N.; Koolen, H.H.F. Determination of the phenolic composition from Brazilian tropical fruits by UHPLC-MS/MS. Food Chem. 2015, 180, 280-287. [CrossRef]

50. Larit, F.; León, F.; Benyahia, S.; Cutler, S.J. Total Phenolic and Flavonoid Content and Biological Activities of Extracts and Isolated Compounds of Cytisus villosus Pourr. Biomolecules 2019, 9, 732. [CrossRef]

51. Provenzano, F.; Sánchez, J.L.; Rao, E.; Santonocito, R.; Ditta, L.A.; Borrás Linares, I.; Passantino, R.; Campisi, P.; Dia, M.G.; Costa, M.A.; et al. Water Extract of Cryphaea heteromalla (Hedw.) D. Mohr Bryophyte as a Natural Powerful Source of Biologically Active Compounds. Int. J. Mol. Sci. 2019, 20, 5560. [CrossRef] [PubMed]

52. Duymuş, H.G.; Göger, F.; Başer, K.H.C. In vitro antioxidant properties and Anthocyanin compositions of elderberry extracts. Food Chem. 2014, 155, 112-119. [CrossRef] [PubMed]

53. Ti, H.; Li, Q.; Zhang, R.; Zhang, M.; Deng, Y.; Wei, Z.; Chi, J.; Zhang, Y. Free and bound phenolic profiles and antioxidant activity of milled fractions of different indica rice varieties cultivated in southern China. Food Chem. 2014, 159, 166-174. [CrossRef] [PubMed]

54. Liazid, A.; Guerrero, R.F.; Cantos, E.; Palma, M.; Barroso, C.G. Microwave assisted extraction of Anthocyanins from grape skins. Food Chem. 2011, 124, 1238-1243. [CrossRef]

55. Liazid, A.; Palma, M.; Brigui, J.; Barroso, C.G. Investigation on phenolic compounds stability during microwave-assisted extraction. J. Chromatogr. A 2007, 1140, 29-34. [CrossRef] [PubMed]

56. Singleton, V.L.; Rossi, J.A. Colorimetry of Total Phenolics with Phosphomolybdic-Phosphotungstic Acid Reagents. Am. J. Enol. Vitic. 1965, 13, 144-158.

57. Singleton, V.L.; Orthofer, R.; Lamuela-Raventós, R.M. Analysis of total phenols and other oxidation substrates and antioxidants by means of folin-ciocalteu reagent. Methods Enzymol. 1999, 299, 152-178. [CrossRef]

58. Machado, A.P.D.F.; Pasquel-Reátegui, J.L.; Barbero, G.F.; Martínez, J. Pressurized liquid extraction of bioactive compounds from blackberry (Rubus fruticosus L.) residues: A comparison with conventional methods. Food Res. Int. 2015, 77, 675-683. [CrossRef]

59. Shang, Y.F.; Kim, S.M.; Um, B.-H. Optimisation of pressurised liquid extraction of antioxidants from black bamboo leaves. Food Chem. 2014, 154, 164-170. [CrossRef] 
60. Kumar, M.; Dahuja, A.; Sachdev, A.; Kaur, C.; Varghese, E.; Saha, S.; Sairam, K.V.S.S. Valorisation of black carrot pomace: Microwave assisted extraction of bioactive phytoceuticals and antioxidant activity using Box-Behnken design. J. Food Sci. Technol. 2019, 56, 995-1007. [CrossRef]

61. Paucar-Menacho, L.M.; Martínez-Villaluenga, C.; Dueñas, M.; Frias, J.; Peñas, E. Response surface optimisation of germination conditions to improve the accumulation of bioactive compounds and the antioxidant activity in quinoa. Int. J. Food Sci. Technol. 2018, 53, 516-524. [CrossRef]

62. Verbeyst, L.; Oey, I.; Van der Plancken, I.; Hendrickx, M.; Van Loey, A. Kinetic study on the thermal and pressure degradation of Anthocyanins in strawberries. Food Chem. 2010, 123, 269-274. [CrossRef]

(C) 2020 by the authors. Licensee MDPI, Basel, Switzerland. This article is an open access article distributed under the terms and conditions of the Creative Commons Attribution (CC BY) license (http://creativecommons.org/licenses/by/4.0/). 